\title{
16. MAGNETOSTRATIGRAPHY OF CARIBBEAN SITE 502 HYDRAULIC PISTON CORES ${ }^{1}$
}

\author{
Dennis V. Kent and Dann J. Spariosu, Lamont-Doherty Geological Observatory and \\ Department of Geological Sciences, Columbia University, Palisades, New York
}

\section{INTRODUCTION}

Obtaining long, continuous, and undisturbed sections of unconsolidated Neogene deep sea sedimentary sections has been limited by (1) practical length of piston cores to about 30 meters and (2) disturbance of sediment by rotary drilling with Glomar Challenger. The relatively high deposition rates of late Neogene sediments in the North Atlantic and in the Caribbean in particular has limited penetration, with conventional piston coring, to sediments not much older than late Pliocene in the Atlantic and not even through the late Pleistocene in the Caribbean. Rotary drilling has penetrated much older sediments in both areas, but the cores suffered extensive drilling disturbance that seriously degrades the paleomagnetism of the material. Utilization of the hydraulic piston corer on the Challenger combines the advantage of a generally undisturbed recovery and great penetration to produce long, relatively undisturbed sections of late Neogene and Quaternary sediments suitable for paleomagnetic studies. In this chapter we present paleomagnetic data from Site 502 .

We tried to determine relative azimuthal orientation of successive cores (see Introduction for details). Because the low latitude of the site meant a small (inclination of about $22^{\circ}$ ) vertical component of magnetization, reversals of magnetization could easily be detected only in changes in the horizontal component, as $180^{\circ}$ shifts in the declination direction of magnetization. Based on information from the core orienting device, a fiducial line was drawn the length of each core prior to cutting it into the standard 1.5 meter sections.

After initial processing (labeling), the core sections were delivered whole to the paleomagnetic laboratory for measurement on a long-core spinner magnetometer. Measurements of the intensity and direction of the component of the natural remanent magnetization in the horizontal (perpendicular to the core axis) with reference to the fiducial line were made nominally at $10-\mathrm{cm}$ intervals for all sections. A total of 600 meters of core was recovered at Site 502 , so that approximately 6000 levels were measured at this site with the long-core spinner magnetometer on board Glomar Challenger.

Since the long-core spinner magnetometer had not been used with much success on board the Challenger, we measured the noise level and the response to establish the limits of resolution for the instrument. 'The

\footnotetext{
${ }^{1}$ Prell, W. L., Gardner, J. V., et al., Init. Repts. DSDP, 68: Washington (U.S. Govt. Printing Office).
}

magnetometer was calibrated with a standard magnetic needle of known magnetization intensity and direction, and 20 successive measurements for different spin integrations were then made on the empty holder. Instrument noise, estimated as the root-mean square of the maximum differences for the two orthogonal measurement axes, varied inversely with the number of spins integrated (Fig. 1), as expected. The Site 502 sediments typically gave intensity readings of about $10^{-3} \mathrm{emu}$ (total moment) or better, so that instrument noise was not usually an important limiting factor in resolving the magnetization direction. A spin integration of $2^{6}$ was typically used for each measurement, which for the magnetometer rotation rate of $7 \mathrm{~Hz}$ required less than $10 \mathrm{~s}$.

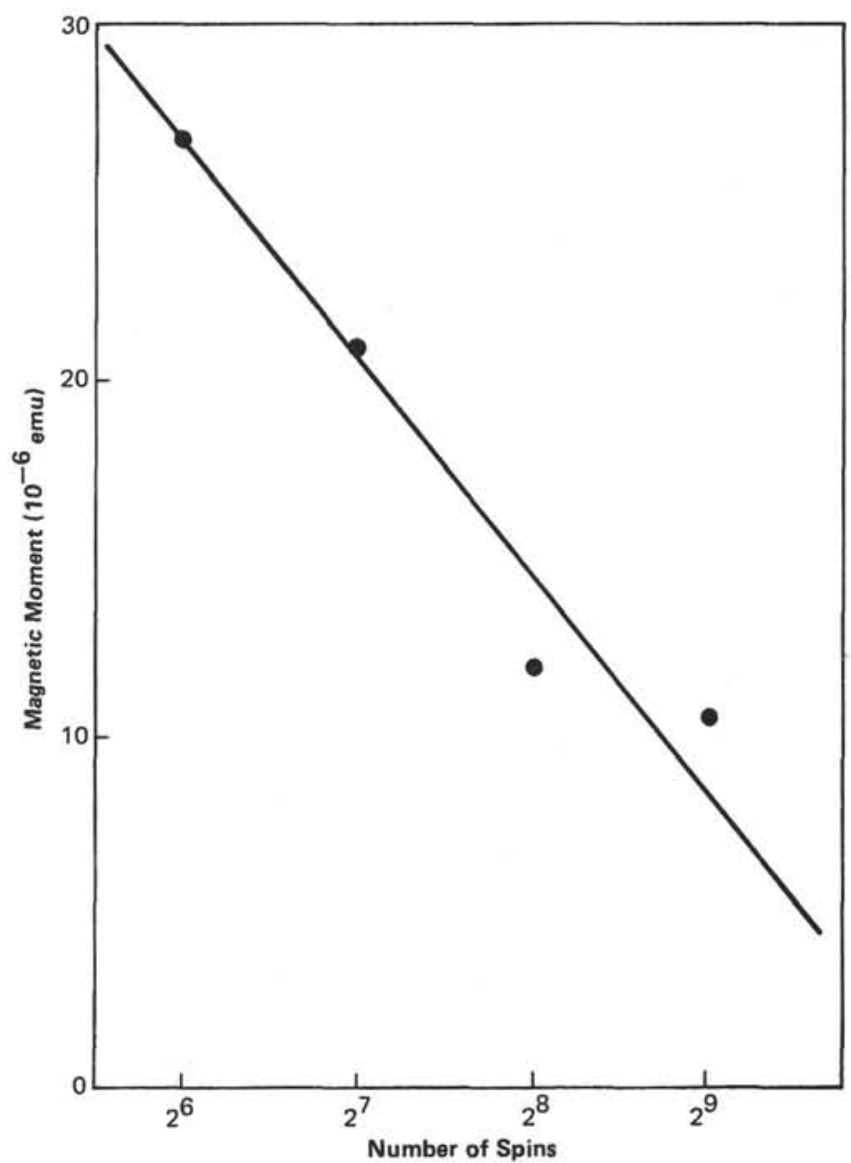

Figure 1. Measurement of noise level of long-core spinner magnetometer onboard Glomar Challenger. Noise is defined as the maximum difference in total magnetic moment over 20 successive measurements for each spin integration. 
The response of the magnetometer was determined by measuring the standard magnetic needle with the sensor at successively greater distances along the rotation axis. The resulting curve (Fig. 2) shows that the response drops at a distance of about $5 \mathrm{~cm}$ to $10 \%$ of the value in the most sensitive region. The response curve also gives some indication of the length of sediment core over which the magnetometer will integrate. Although averaging of the sediment magnetization signal over several centimenters along the core axis is difficult to overcome with such an instrument, readings taken at intervals of $10 \mathrm{~cm}$ or more will be essentially independent.

In addition to the long-core measurements, we also measured the magnetization of one or more discrete samples from each section on a conventional spinner magnetometer. This allows us to investigate the stability of magnetization in order to assess the reliability of the undemagnetized NRM measurements with the long-core magnetometer, to determine the inclination directions of the magnetization as an aid to polarity determination, and to provide a check on the long-core magnetometer measurements in general.

\section{Magnetic Properties}

On the basis of progressive AF demagnetization experiments, the NRM of sediments at Site 502 are judged to be generally stable, with some notable exceptions. Figure 3 is a plot of the ratio $J_{50} / J_{\mathrm{NRM}}$, the magnetization remaining after $\mathrm{AF}$ demagnetization at $50 \mathrm{Oe}$ to the initial NRM intensity, against the sub-bottom depth at Site 502 . This ratio is typically close to unity in the upper 90 meters, indicating that low coercivity magnetiza-

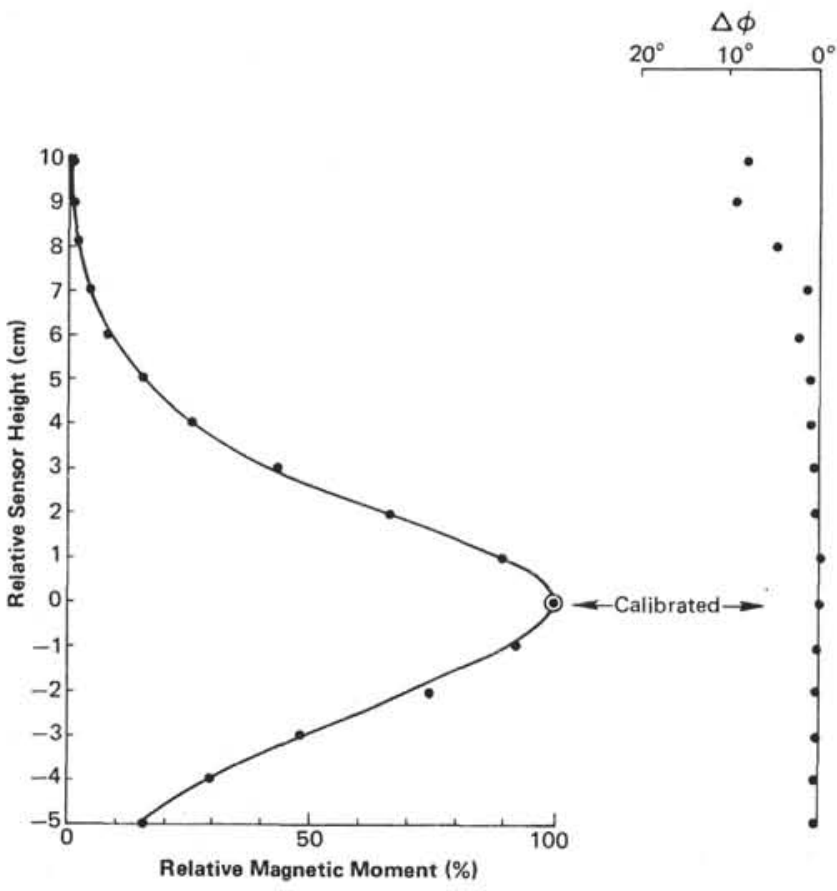

Figure 2. Response of long-core spinner magnetometer to calibration magnetic needle with distance along spin axis. The resulting curve gives an indication of the amount of sediment core that will contribute to the magnetization at any particular level. tions are relatively small. In the interval between approximately 90 and 120 meters, this ratio is often much greater than unity, whereas between 130 and 170 meters it is characteristically much less than unity. These departures from unity imply the presence of larger low coercivity magnetizations. The ratio values greater than unity suggest a substantial low coercivity component directed antiparallel to a more stable magnetization. Indeed, we interpret this part of the section between 90 and 120 meters as showing a predominantly stable reversed magnetization polarity. The low coercivity component is presumably a secondary magnetization acquired in the present (normal) field. On the other hand, the low $J_{50} / J_{\mathrm{NRM}}$ ratios in the interval between 130 and 170 meters correspond to scattered NRM directions, and the interval appears to be dominated by unstable magnetizations. The lower part of the section, from 170 meters to the base, is again characterized by ratios near unity, with more internally consistent NRM directions.

Vector diagrams illustrating individual sample demagnetization behavior are shown in Figures 4 and 5 . Some samples (Fig. 4A, B, and D) often show an increase in remanent intensity in the initial stages of $\mathrm{AF}$ demagnetization which can be attributed to the progressive removal of a low coercivity component directed in opposition to the more stable reversed characteristic magnetization (with negative inclination) that decays to the origin at higher levels of demagnetization. The NRMs of samples with normal characteristic magnetizations (positive inclination) typically decay linearly to the origin from the outset with progressive AF demagnetization (Fig. 4C).

For both normal and reversed magnetic polarity samples, the NRM declination directions generally agreed closely with the long-core declination measurements. It is therefore possible to infer the polarity corresponding to the long-core declinations in individual cores from the sign of the inclination in conjunction with the behavior of the sample remanent vector during progressive AF demagnetization. Although this technique of polarity determination can readily be applied in the upper 50 meters of section, reliability decreases with depth up to approximately 140 meters, below which we have not yet been able to establish the sense of polarity for any cores. This decrease in utility is due to an apparent shallowing of the inclinations, combined with an increase in unstable magnetization, with depth.

The decrease in magnetization stability with depth, particularly below 140 meters, is indicated by relatively low values of $J_{50} / J_{\text {NRM }}$ (Fig. 4). Vector demagnetization diagrams (Fig. 5) show that the shallow inclinations are characteristic of samples from lower levels, and since they persist to high alternating fields, they cannot be ascribed to instability of magnetization.

The magnetically cleaned sample inclinations measure aboard the Challenger are plotted with respect to depth in section in Figure 6. The expected dipole inclinations for the site latitude is $22^{\circ}$. In the upper 50 meters the sample inclinations, irrespective of sign, appear to be distributed about this value, but the distribution of inclinations becomes skewed to lower values with greater 


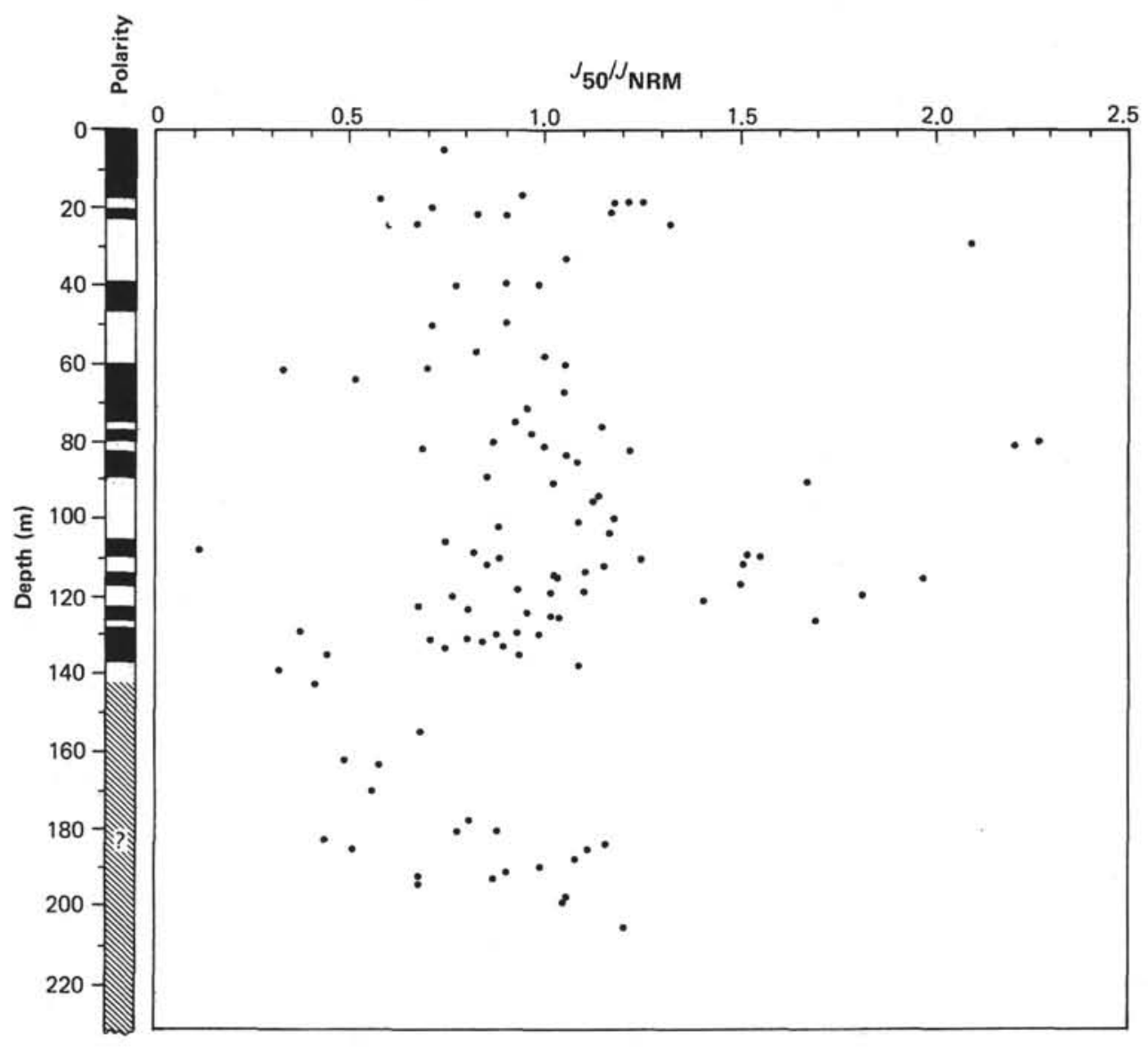

Figure 3. The magnetization remaining after AF demagnetization at 50 Oe to the initial NRM intensity $\left(J_{50} / J_{\text {NRM }}\right)$ against sub-bottom depth at Site 502 . This ratio is a measure of the importance of low coercivity magnetization, values near to unity indicating small soft magnetization and lower and higher values indicating larger soft components. (All sample magnetizations measured onboard Challenger.)

depth in section. In the interval 125 to 150 meters, about $65 \%$ of the sample inclinations are less than $10^{\circ}$. A change of $10^{\circ}$ in dipole field inclination might be attributéd to a change of about $5^{\circ}$ in site latitude, but there is little evidence of such plate motion in the Caribbean over the time represented at Site 502 (approximately 5 m.y.). We therefore suspect that the apparent trend of shallower than expected magnetic inclinations with depth in section may be related to the effects of sediment compaction. We note that there is a progressive increase in sediment shear strength with depth (see Mayer, this volume) and a pronounced gradient at about 125 meters. The relative change in shear strength may be related at least in part to greater compaction of the sediment. In particular, the marked increase in shear strength at about 125 meters corresponds roughly to the level at which the inclinations become highly skewed to low values. However, we also note that there may be a change in the trend of shallowing inclinations near the base of the section $(150-200 \mathrm{~m})$, where the sample inclinations become more evenly distributed over the range $0^{\circ}$ to $30^{\circ}$. This change in trend may correspond to a change in gross lithology and a corresponding change in sediment magnetization with compaction. It will be interesting to see if there is any systematic change in mag- netic fabric with depth in sediments that may be more directly affected by compaction.

\section{PRESENTATION OF RESULTS}

\section{General Considerations}

Complete interpretation of the magnetic polarity zonation in each hole was complicated by several factors. Foremost was the failure of the orienting device to provide consistent relative azimuthal orientation among cores. The internal consistency of the paleomagnetic data within the cores is usually high. The declination directions with reference to the fiducial line generally fall in a narrow range of azimuths, with occasional $180^{\circ}$ shifts within cores, indicating reversals of magnetization polarity. It is therefore reasonable to assume that the internally consistent declination directions within cores represent a record of either normal or reversed magnetic polarity. The efficacy of the orienting device was tested by determining the amount of rotation required to bring these well-grouped declinations within each core to a $\mathrm{N}-\mathrm{S}$ horizontal axis, corresponding to the directions of a normal or reversed field direction. These corrections are plotted on a rose diagram (Fig. 7) for 95 cores at Site 502. Because it was evident that no distinct grouping of 

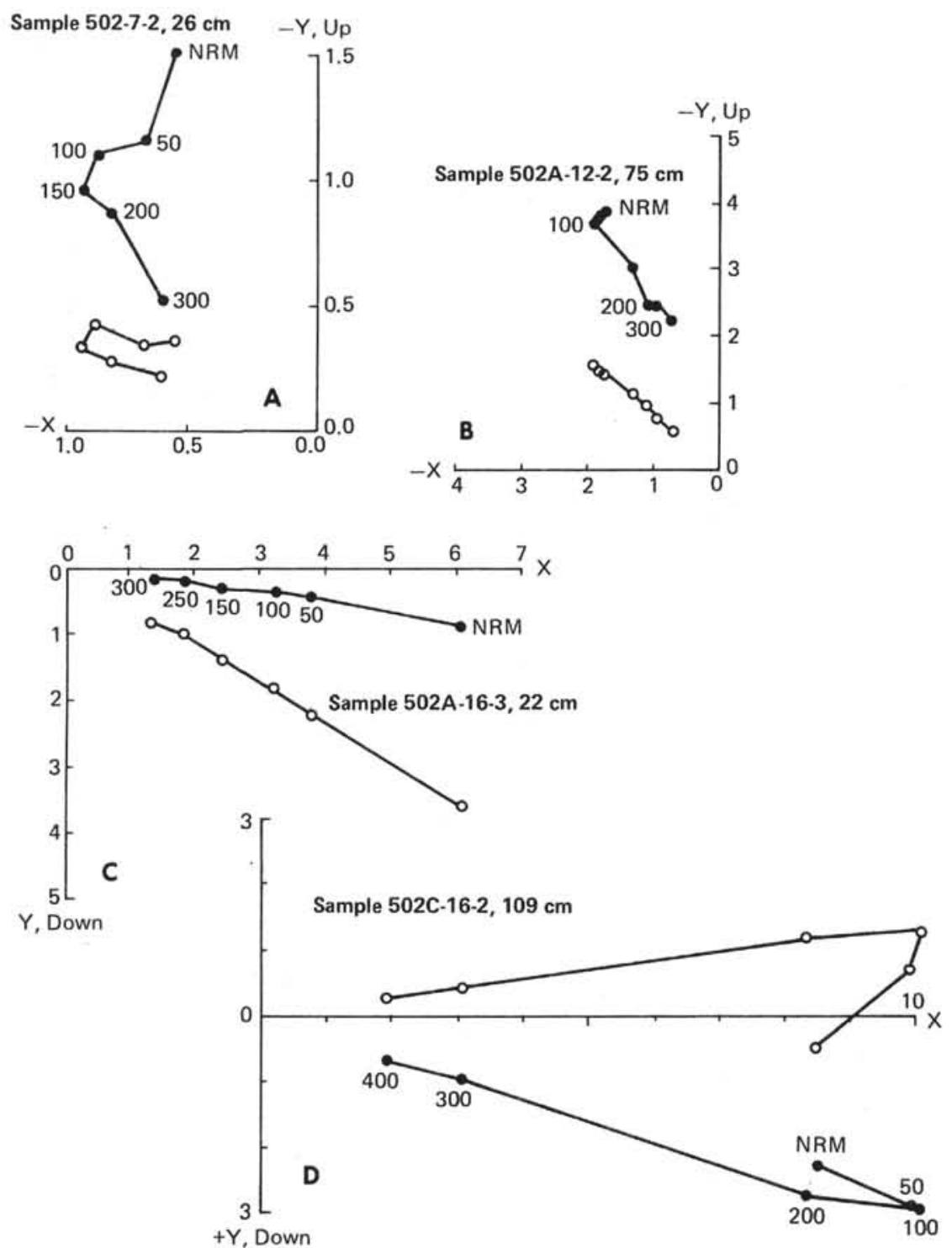

Figure 4. Representative vector end-point diagram of progressive AF demagnetization of NRM of samples from upper $102 \mathrm{~m}$ of section at Site 502. Solid and open circles are projections of vector end-points on horizontal and $\mathrm{N}-\mathrm{S} \mathrm{X}$, vertical planes, respectively. Magnetization units on axes in $10^{-6} \mathrm{G}\left(10^{-3} \mathrm{Am}^{-1}\right)$. Numbers adjacent to symbols are AF demagnetization level in Oe.

azimuthal corrections occurs, we could not rely on the core orientation information to determine the sense of polarity from one core to another and had to interpret it within each core by other criteria.

These criteria included consideration of (1) the inclination component of the discrete magnetic samples taken from each core section and the behavior of the sample magnetizations during progressive alternating field demagnetization; (2) the consistency of the inferred magnetic polarity logs between holes; and, finally, (3) the consistency of the composite polarity log at the site with the known record of geomagnetic reversals in the time interval constrained by biostratigraphic information.

By these methods it was possible to construct a composite magnetostratigraphy for Site 502 to a depth of approximately 145 meters, near the level of the Mio-
cene/Pliocene boundary. We have not yet found it possible to interpret the magnetic polarity of the cores below this level, primarily because the inclination component of the sample magnetizations becomes very shallow. The sense of the inclinations-whether upward or downward, corresponding to reversed or normal polarities-is therefore difficult to resolve with any degree of confidence.

\section{Composite Polarity Log for Site 502}

The levels of reversals of magnetization polarity at each of the holes at Site $\mathbf{5 0 2}$ are shown in Table 1. The magnetization reversals levels listed are those which occur as $180^{\circ}$ shifts in declination within individual cores and do not include the magnetization reversals we suspect occur between cores. In all cases, the $180^{\circ}$ shifts in 

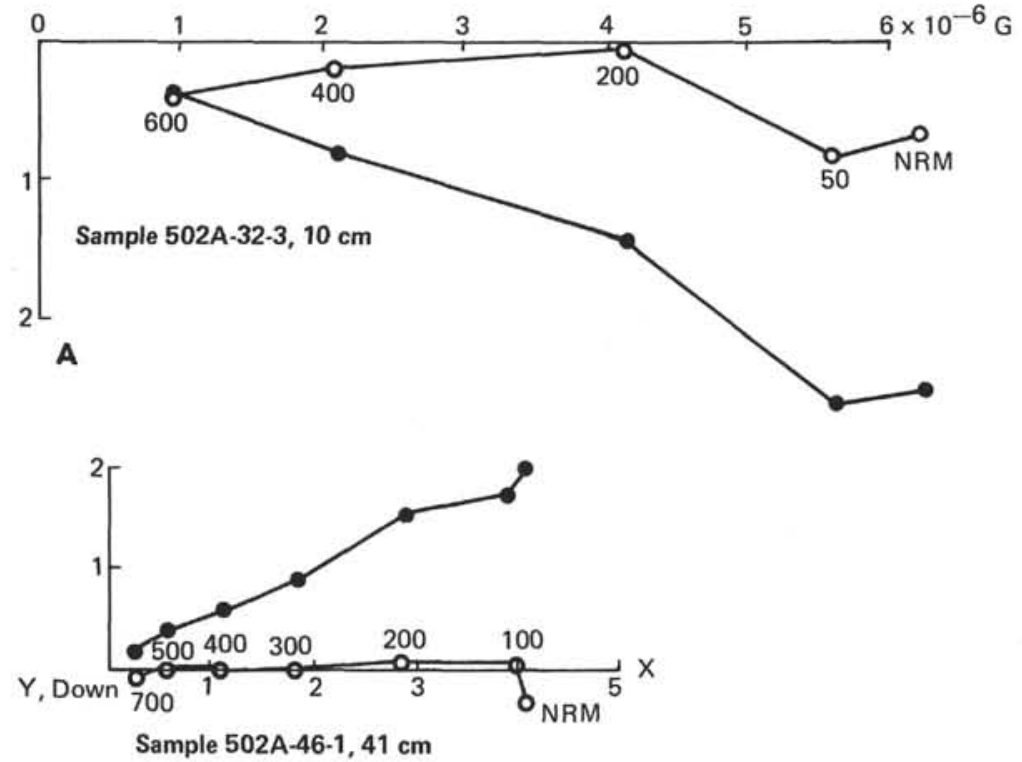

B

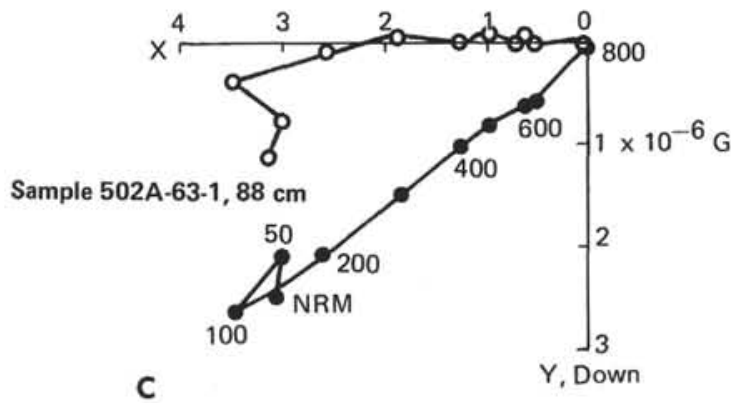

Figure 5. Representative vector end-point diagrams of progressive AF demagnetization of NRM of samples from the lower part of the section at Site 502 .

declination from the long-core measurements have been verified by individual sample measurements as representative of the stable component of magnetization. In many cases, particularly in the upper 120 meters of section, the sense of the polarity change, either from normal to reversed or reversed to normal, can be reasonably determined from nearby sample inclinations and the behavior of the NRMs during progressive AF demagnetization. Assuming that a complete section of Plio-Pleistocene sediments are present at Site 502, as indicated by the biostratigraphy, it is possible to correlate the stratigraphic sequence of magnetozones with the known record of magnetochrons in this time interval. Although the interpretation of magnetozones within each hole is to some extent dependent on the integration of paleomagnetic data from all four holes, we in retrospect indicate in Table 1 the likely correlation of magnetozone with magnetic chron boundaries for convenience of discussion.

In presenting a composite magnetostratigraphy for Site 502, we adjusted the mean declination directions within each core to either $0^{\circ}$ or $180^{\circ}$, depending upon our interpretation of the polarity (normal or reversed) of the corresponding interval. We emphasize that because of the absence of reliable relative azimuthal orientation of the cores and because of the difficulty in resolving the polarity within many cores from the sample inclination values, particularly at deeper levels in the section, the interpretation of polarity in any core may not be unique. For this reason we delimit the core intervals in Figure 8; alternative interpretations of the magnetostratigraphy may be obtained simply by readjusting the declinations of any core. However, we feel that the interpretation we present in Figure 8 is the most consistent with the paleomagnetic and biostratigraphic data available.

\section{Discussion}

There are 19 polarity reversals (Fig. 9) that define the well-established succession of normal and reversed polarity intervals in the Plio-Pleistocene. Between 6 and 12 of these are recorded within cores as $180^{\circ}$ shifts in declination at any individual hole at Site 502. The remaining polarity transitions at each hole were apparently missed because of poor data related to core disturbance or lack of core recovery across critical levels in the sediment column. Nevertheless, all 19 polarity transitions are recorded, taking the four holes at Site 502 together, and most occur in at least two holes (Table 1). Identification of the same polarity transitions in two or more adjacent holes is the basis of developing a composite magnetostratigraphy for Site 502 , comprised of overlapping segments from various holes for the upper 145 meters of section. 


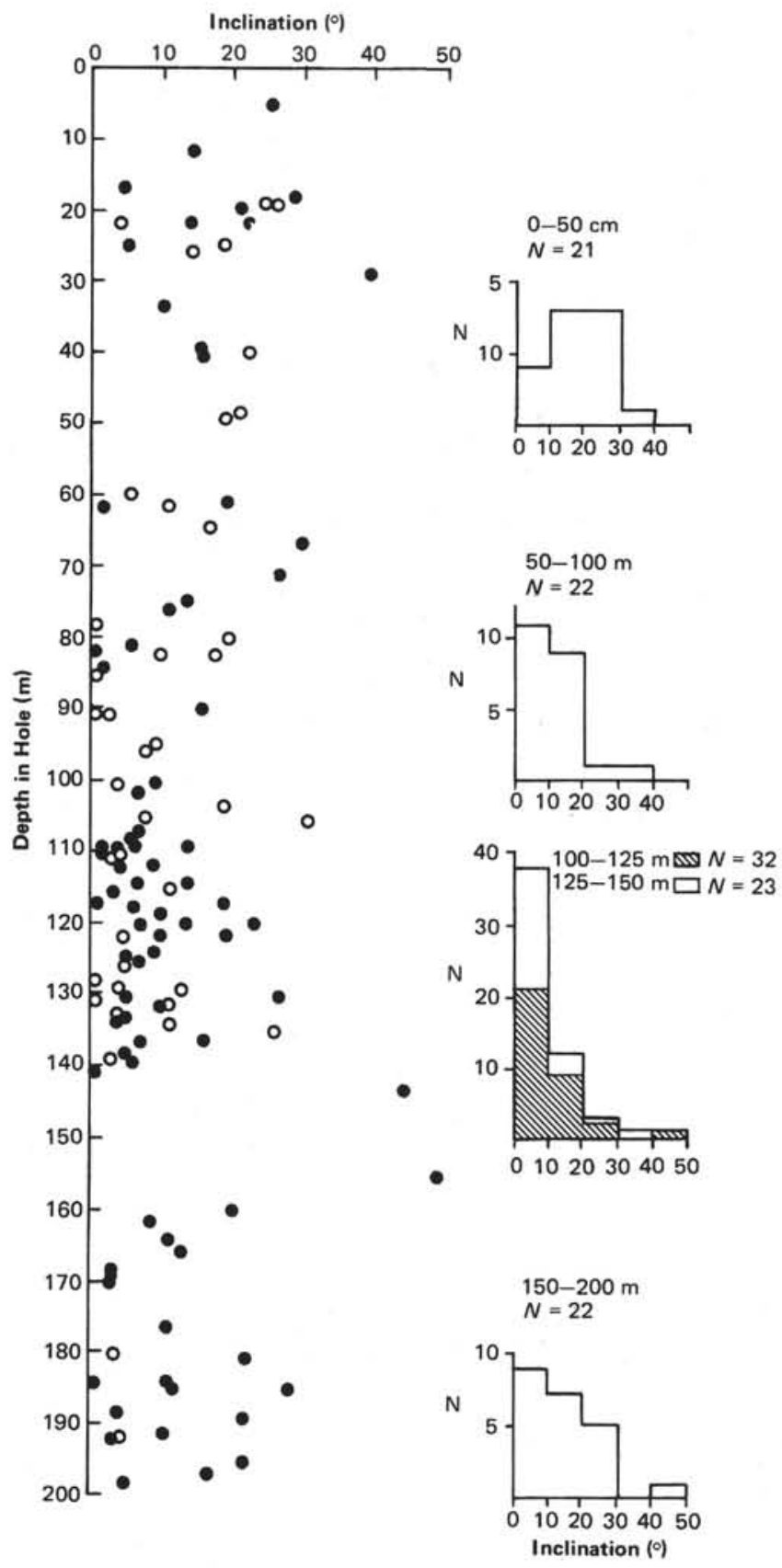

Figure 6. Magnetically cleaned sample inclinations (open circles, negative; solid circles, positive) plotted against depth in section at Site 502 . Histograms show distribution of inclinations (absolute values) for different depth intervals.

It should be noted that the sub-bottom depths to what we consider to be correlative magnetostratigraphic horizons are often offset by as much as 10 meters among the adjacent holes at Site 502 . We ascribe at least a major portion of these offsets to the rather crude method employed to measure the drill string - and hence the cored intervals-on the ship. Admittedly, however, the problem of inconsistent sub-bottom depths among the individual holes adds yet another variable to be taken into account in establishing a composite magnetostratigraphic section for Site 502 .
Several features of this composite magnetostratigraphy for the Plio-Pleistocene sediments at Site 502 are worth mentioning. In the vicinity of the magnetozone correlated to the Jaramillo, we observe several short intervals of normal polarity that appear to be consistently present in two or more holes (Fig. 10). Some of these features may reflect short period reversals of the geomagnetic field. Although we observed several anomalous inclination values, samples from these subzones generally agreed in declination with long-core measurements. Low measured intensities throughout this sequence (Fig. 8), together with the anomalous directions, may record a period of less stable geomagnetic field behavior during the late Matuyama chron. We note that either Magnetosubzone C or D may be correlative with the Cobb Mountain subchron of Mankinen et al., (1978), whereas either A or B may record the same paleomagnetic features described by Watkins (1968) in several deep sea sediment cores.

The normal magnetozone we correlate to the Olduvai subchron (Fig. 8) was generally not well recorded owing to poor undisturbed core recovery in this interval. It is therefore not entirely clear if the change in magnetization polarity at the top of Core 502A-12 is a record of the base of the Olduvai. Although we associate the base of the Olduvai with this reversal, the short intervals of normal polarity recorded at the top and as well as at the base of Core 12 are at levels correlative with the Reunion subchrons.

The two reversed subchrons recognized within the Gauss are apparently recorded at Site 502, although the Kaena magnetozone in these sediments is characterized by scattered declination directions accompanied by, and perhaps the result of, the low remanent intensities measured on the long-core spinner. However, discrete sample measurements confirm the presence of reversely magnetized sediments in this interval. The low remanent intensities in the interval may be associated with either a change in the geomagnetic field or the magnetic properties of the sediments. The latter seems a more fruitful hypothesis, since similar magnetization characteristics do not occur consistently elsewhere in this time interval. A clear example of lithological control over the magnetism of these sediments is the good correlation of high remanent intensities with the occurrence of volcanic ash layers, as at 132 meters.

All four subchrons of the Gilbert reversed chron are apparently recorded, although the interpretation of polarity in individual cores is somewhat more tenuous in this part of the section because of shallow inclinations. A major stratigraphic aid in correlating the holes is the very distinctive volcanic ash doublet at approximately 132 meters. The top and base of the lower magnetosubzone $\left(\mathrm{C}_{2}\right)$ of the Gilbert are recorded in different holes (Table 1); our assignment of these magnetization polarity reversals as the limits of the $\mathrm{C}_{2}$ magnetosubzone is largely based on the correlation of the ash doublet between Hole 502 and 502A.

We interpret reversely magnetized sediments of the early Gilbert from the base of $\mathrm{C}_{2}$, at approximately 137 meters, to a level at about 143 meters, below which there 


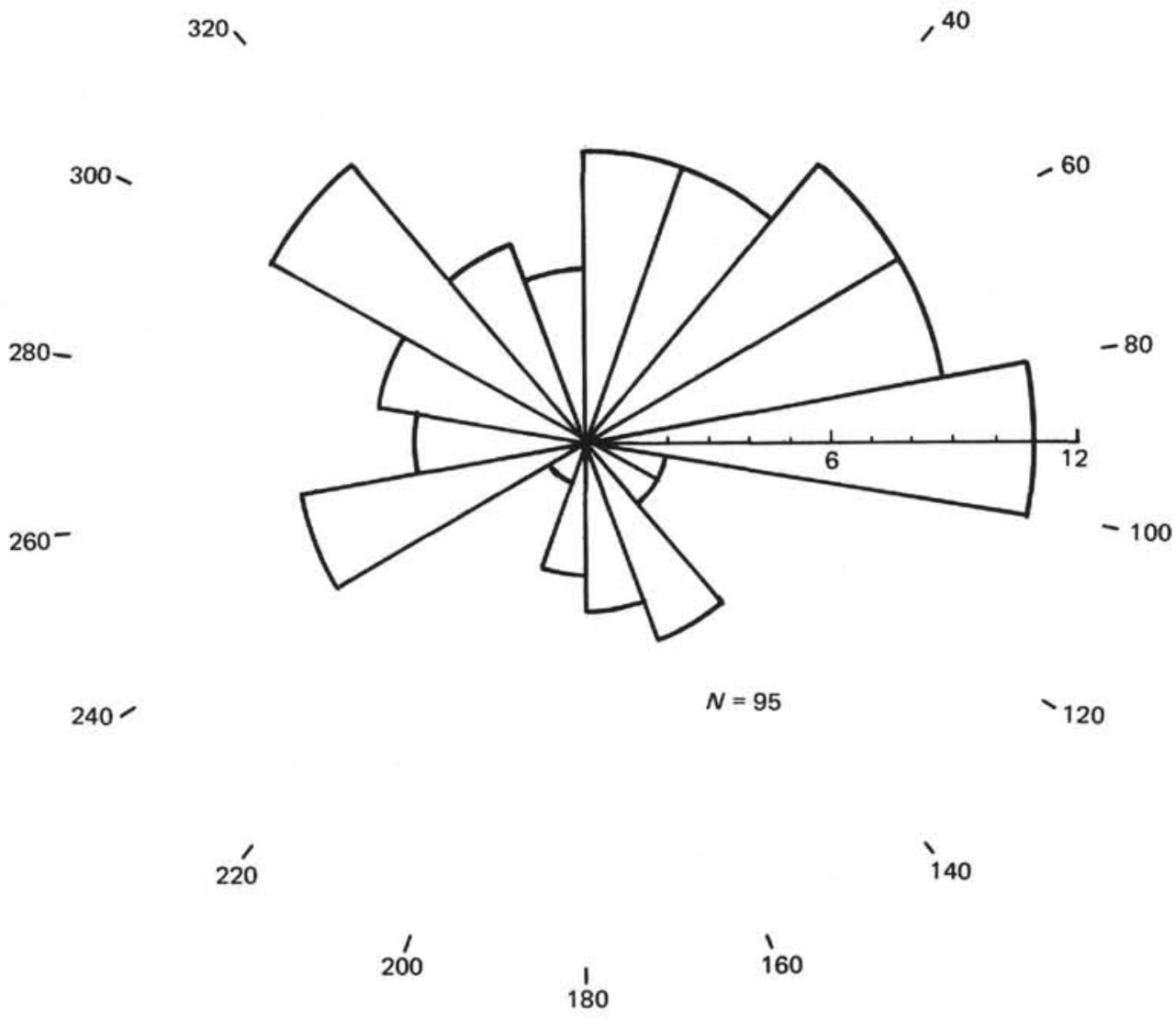

Figure 7. Azimuthal distribution of rotation $\left({ }^{\circ}\right)$ required to bring remanent declinations into north-south direction for 95 cores at Site 502. Lack of distinct grouping is interpreted as indicating poor reliability of the method of core orientation employed at Site 502 .

Table 1. Core, section, and depth in section of intervals corresponding to magnetozone boundaries interpreted in four holes at Site 502 .

\begin{tabular}{|c|c|c|c|c|}
\hline \multirow[b]{2}{*}{ Magnetozone Boundary } & \multicolumn{4}{|c|}{$\begin{array}{c}\text { Sample } \\
\text { (Interval in } \mathrm{cm} \text { ) }\end{array}$} \\
\hline & 502 & S02A & 502B & $502 \mathrm{C}$ \\
\hline & \multicolumn{4}{|c|}{ Jaramillo } \\
\hline top & $6-1,110-145$ & $6-1,80-90$ & - & \\
\hline bottom & $6-3,55-75$ & $6-3,15-25$ & $6-2,45-70$ & \\
\hline \multicolumn{5}{|l|}{ Olduvai } \\
\hline $\begin{array}{l}\text { top } \\
\text { bottom }\end{array}$ & $\begin{array}{c}10-2,120-135 \\
-\end{array}$ & $\begin{array}{l}10-2,105-115 \\
12-1,90-100\end{array}$ & $11-1,90-\overline{110}$ & \\
\hline Matuyama/Gauss & $15-2,115-130$ & $12-1,90-100$ & $11-1,90-110$ & $6-1,125-140$ \\
\hline \multicolumn{5}{|l|}{ Kaena } \\
\hline top & - & $19-1,140-145$ & $18-1,140 ; 18-215$ & $9-1,100-130$ \\
\hline bottom & - & $19-3,20-50$ & $18-3,40-50$ & $9-2,145 ; 9-3,20$ \\
\hline \multicolumn{5}{|l|}{ Mammoth } \\
\hline $\begin{array}{l}\text { top } \\
\text { bottom }\end{array}$ & $\begin{array}{l}20-1,90-105 \\
20-2,145 ; 20-3 \quad 17\end{array}$ & $\begin{array}{c}20-2,90-100 \\
-\end{array}$ & $19-2,110-120$ & $10-2,60-100$ \\
\hline Gauss/Gilbert & $22-1,90-105$ & $22-2,30-70$ & - & - \\
\hline \multicolumn{5}{|l|}{ Cochiti } \\
\hline top & $25-3,75-80$ & - & & $16-2,145 ; 16-3,20$ \\
\hline \multirow{2}{*}{\multicolumn{5}{|c|}{ Nunivak }} \\
\hline & & & & \\
\hline top & - & $28-1,70-90$ & & $18-2,125-130$ \\
\hline \multirow{2}{*}{\multicolumn{5}{|c|}{$\mathrm{C}_{1}$}} \\
\hline & & & & \\
\hline & - & - & & $20-2,70-90$ \\
\hline bottom & $30-3,15-30$ & - & & $21-1,110 ; 21-2,20$ \\
\hline \multicolumn{5}{|r|}{$21+1,700,21-2,20$} \\
\hline top & $31-2,45-60$ & - & & - \\
\hline bottom & - & $34-1,90-100$ & & - \\
\hline
\end{tabular}




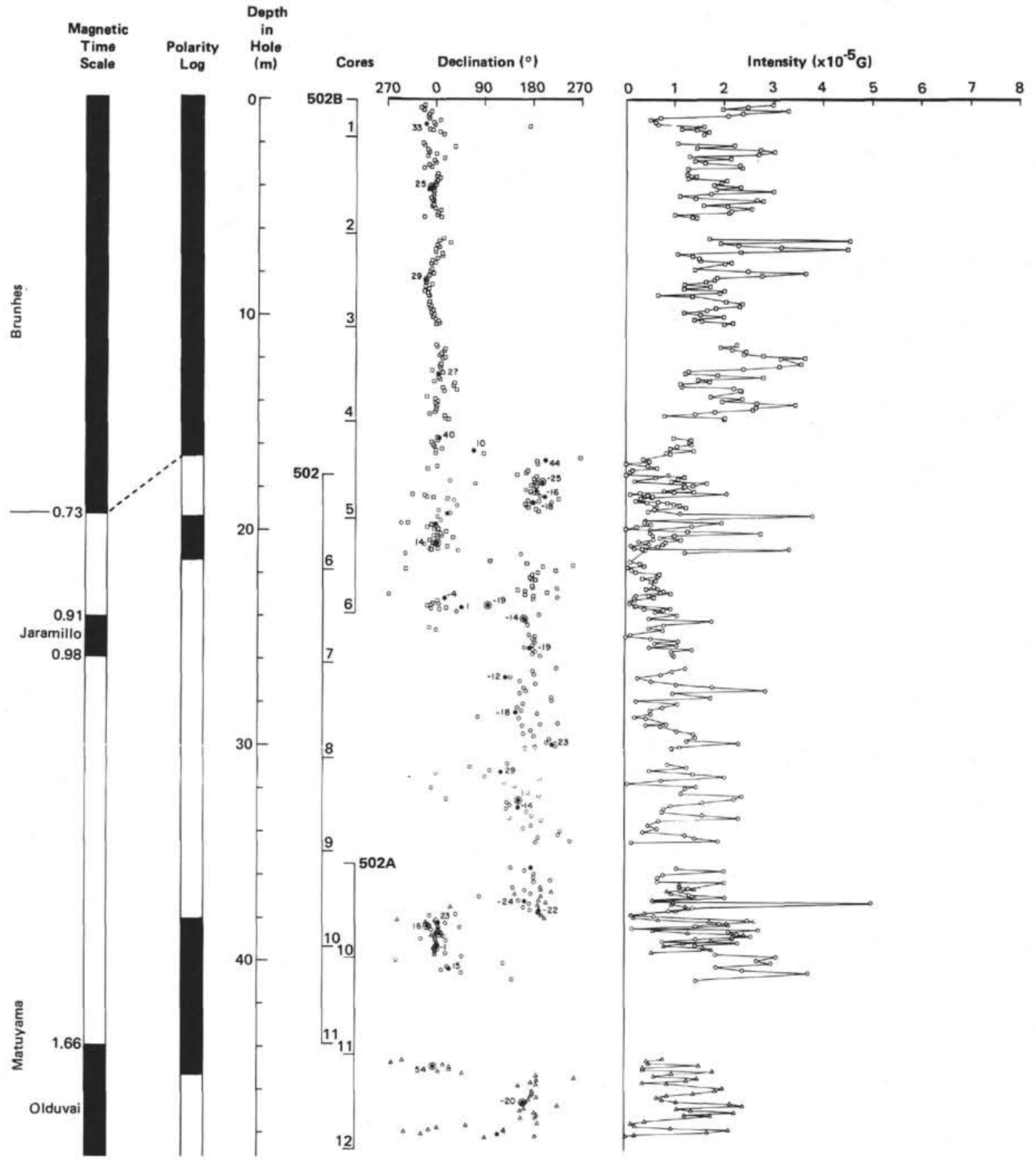

Figure 8. Composite magnetostratigraphy for upper 145 meters of section at Site 502 . Columns from left to right: (1) geomagnetic reversal time scale from LaBrecque et al. (1977) with corrected ages (Ma) after Mankinen and Dalrymple (1979); (2) polarity log of interpreted magnetozones at Site 502, solid (open) bar indicating dominantly normal (reversed) magnetization polarity; (3) depth in section based largely on Hole 502; (4) cores used in assembling composite, from Holes 502, $502 \mathrm{~A}, 502 \mathrm{~B}$, and 502C; (5) remanent declinations measured with long-core spinner magnetometer in Hole 502 (small open circle), 502A (open triangle), 502B (open square), and 502C (x). Solid circles are sample NRM declination measurements and circled solid circles are magnetically cleaned directions; adjacent numbers are the measured inclination values for each sample. Declinations within each core have been uniformly adjusted to average $0^{\circ}$ for a normal polarity interpretation and $180^{\circ}$ for reversed polarity. Only magnetic measurements from sedimentologically disturbed core intervals have been omitted; (6) remanent intensities measured with long-core spinner magnetometer, assuming a sediment volume of approximately $150 \mathrm{~cm}^{3}$ contributes to signal at each level. 


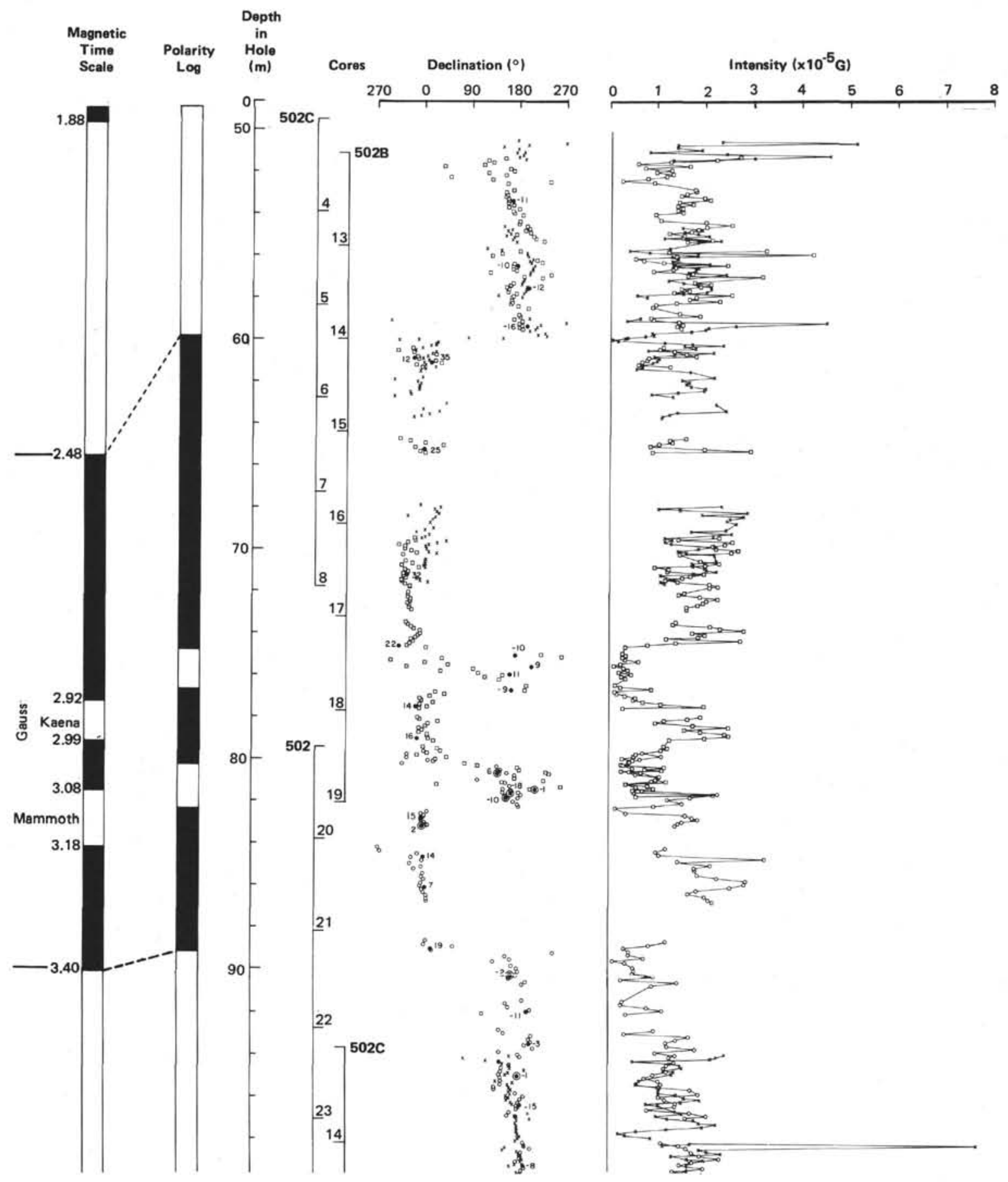

Figure 8. (Continued).

is an interval extending to 164 meters that has poor paleomagnetic data, characterized by scattered directions and low remanent intensities. The transition into this interval can be seen in Cores 502-34 and 502A-35 as a progressive decrease in remanent intensity and an increase in scatter of directions with depth. The marked change in magnetic characteristics coincides approximately with the level of the Miocene-Pliocene boundary in this section. The internal consistency of the paleomagnetic data improves below 164 meters to the base of the recovered section. However, we have not found it possible to assign polarities to any part of the section below 143 meters, with any degree of confidence, even utilizing the discrete sample measurements. This is due to a combination of problems, most important of which is the lack of between-core azimuthal orientations combined with the shallowing of the inclination directions. Consequently the data in Figure 9 are plotted with respect to the arbitrary fiducial line for each core, and no attempt has been made to adjust the declination to the expected north-south orientation.

A curious feature of the paleomagnetic record between 143 meters and the base of the recovered section at approximately $\mathbf{2 1 6}$ meters is that, compared with the 


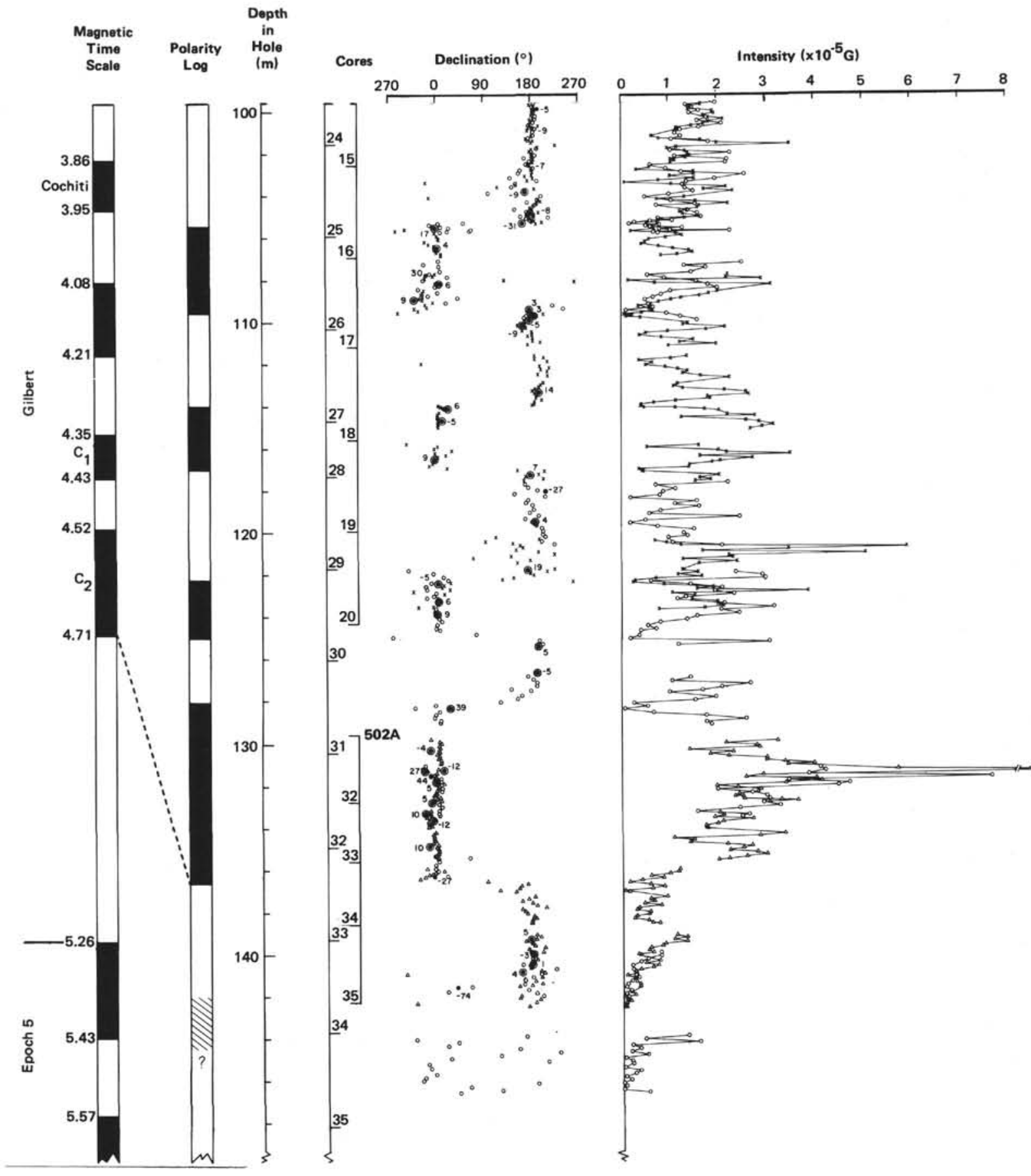

Figure 8. (Continued).

upper part of the section, there seem to be very few magnetization polarity reversals recorded within cores, either in the long-core data or in the magnetically cleaned discrete sample measurements. In Hole 502, there is some evidence of a polarity reversal in Core 40 and perhaps in Core 47, whereas in Hole 502A only Core 44 provides possible evidence of a reversal. Since the geomagnetic reversal frequency is not very different over the Neogene, this observation might suggest that the section below 143 meters represents a relatively short period of time (i.e., it was deposited at a higher deposition rate than the upper part of the section) and does not encompass very many geomagnetic polarity changes.

\section{SEDIMENTATION RATES}

Correlation of sediment magnetozones to the welldated sequence of geomagnetic polarity reversals in the Neogene allows the determination of relatively precise sedimentation rates, even over short intervals. Figure 11 shows a plot of sub-bottom depths to magnetozone identified at Site 502 with respect to the age of their correlative magnetic chrons and subchrons according to the time scale of LaBrecque et al., (1977). The slope of the line drawn through the points is a measure of the sedimentation rate for a given interval. The regular nature of the sedimentation rate plot provides further support 
for our interpretation of the magnetostratigraphy at Site 502. Sedimentation rates generally increase with depth in section-from about $24 \mathrm{~m} / \mathrm{m}$.y. during the Brunhes and Matuyama, $32 \mathrm{~m} / \mathrm{m}$.y. during the Gauss, and 36 $\mathrm{m} / \mathrm{m} . \mathrm{y}$. in the Gilbert. The magnetostratigraphy could not be established in the lower third of the section. However, the $A$. primus datum, which occurs at approximately the 195 meter level, has been placed within Chron 6 and dated thereby at about $6.25 \mathrm{Ma}$ (Haq et al., 1980). This information indicates a further increase in average sedimentation rate to about $38 \mathrm{~m} / \mathrm{m} . \mathrm{y}$. for the interval between the base of $\mathrm{C}_{2}(137 \mathrm{~m})$ and the $\mathrm{A}$. primus datum $(195 \mathrm{~m})$. The biostratigraphic information also suggests that only four polarity transitions, those defining Chron 5 and Subchron A, are expected to occur in the interval 143 to 195 meters, which could explain why there are so few magnetization reversals in this part of the section.

Included in this generally uniform trend of increasing sedimentation rates with depth are larger variations over shorter time intervals. As a matter of interest, sedimentation rates at the level of resolution of subchrons vary from about $17 \mathrm{~m} / \mathrm{m} . \mathrm{y}$. in the reversed interval between the Brunhes and the top of the Jaramillo to $45 \mathrm{~m} / \mathrm{m}$.y. within Subchronozones $\mathrm{C}_{1}$ and $\mathrm{C}_{2}$ of the Gilbert.

\section{FINAL REMARKS}

Our experience with the hydraulic piston corer on the Glomar Challenger indicates an unparalleled opportunity now available to obtain long, undisturbed sections of relatively unconsolidated sediment suitable for detailed magnetostratigraphic studies. Although the drill string allows great penetration, far in excess of the capabilities of the conventional piston corer deployed from an oceanographic vessel, the hydraulic device avoids much of the disturbance typically associated with rotary drilling which heretofore severely limited the utility of DSDP cores for paleomagnetic investigations. Our initial overall success in obtaining good magnetostratigraphic records from unconsolidated sediment on Leg 68, particularly at Site 502 , is a clear indication of the great potential of hydraulic piston coring technology for addressing a wide variety of stratigraphic, paleoceanographic, sedimentological, and related studies that require a long, complete, detailed record of relatively unconsolidated sedimentary sections in various areas of the world ocean.

Our experience also indicates, however, that some modifications to coring methodology will be required if this potential is to be fully realized, at least for obtaining reliable paleomagnetic records. Unlike most other parameters measured on sediment cores, paleomagnetism is critically dependent on preserving the original fabric, composition, and orientation. Disruption of the fabric-for example, during core handling-change in composition-notably the introduction of highly magnetic material like rust scale-and lack of relative coreto-core azimuthal orientation seriously impair our ability to interpret the paleomagnetic record. Some of these problems-for example, disruption of fabric and exposure to extraneous magnetic fields - can be easily minimized by minor modifications to existing procedures.
Others, particularly rust scale and core-to-core azimuthal orientation, require more concerted efforts.

\section{Rust Scale}

Short of replacing the drill string with coated or nonferrous pipe, it seems to us that rust scale within the existing drill pipes can be greatly reduced by some procedure whereby the pipe interiors might be wire-brushed, sprayed with antioxidant, and left capped to prevent further corrosion from salt spray until ready for use. As noted earlier, because rust scale is typically confined to the outer surface of undisturbed sediment cores, samples from interior portions do not seem to be contaminated. Nevertheless, the presence of rust scale within the core liner makes long-core spinner magnetometer measurements virtually useless. Consequently, instead of being able to make rapid measurements of sediment magnetism with the long-core spinner, with occasional spot sampling to test magnetic stability, the paleomagnetist must resort to extensive sampling of the cores, which means a concomitantly great expenditure of personnel effort part as well as deterioration of the working halves of the cores. It is not even clear that discrete sample measurements provide significantly better magnetostratigraphic data, particularly in equatorial latitudes where the magnetization of the sediment lies predominantly in the plane of measurement of the long-core spinner.

\section{Azimuthal Orientation}

Relative azimuthal orientation is absolutely essential in coring at equatorial latitudes, either with discrete sample or long-core spinner measurements, because the vertical component of magnetization is too small to be very useful in establishing polarity. At higher latitudes, magnetization polarity can be determined by discrete sample measurements without azimuthal orientation of cores, but since the long-core spinner measures only the horizontal component of magnetization, core-to-core azimuthal orientation is required if this instrument is to be used effectively.

It seems to us that the hydraulic piston core device could be made to seat positively within the bottom-hole assembly, in the same orientation with respect to the drill string at each insertion. Relative ccre-to-core azimuthal orientation can then be maintained by monitoring the position of the drill string when the hydraulic piston corer is fixed. Such a technique might even provide absolute orientation with respect to the known heading of the vessel. An orienting procedure along these lines would obviate the need for the orienting rings now in use which often have multiple marks and are difficult to interpret.

Proper conditions for the use of the long-core spinner magnetometer represent an important rationale for the presence of a paleomagnetist on board Glomar Challenger. Measurements with this instrument are rapid, nondestructive, and can be made only before the cores are routinely split. Otherwise, discrete samples can just as easily be taken and measured at shore-based facilitiesbut even then, equatorial latitude sediments cannot be 


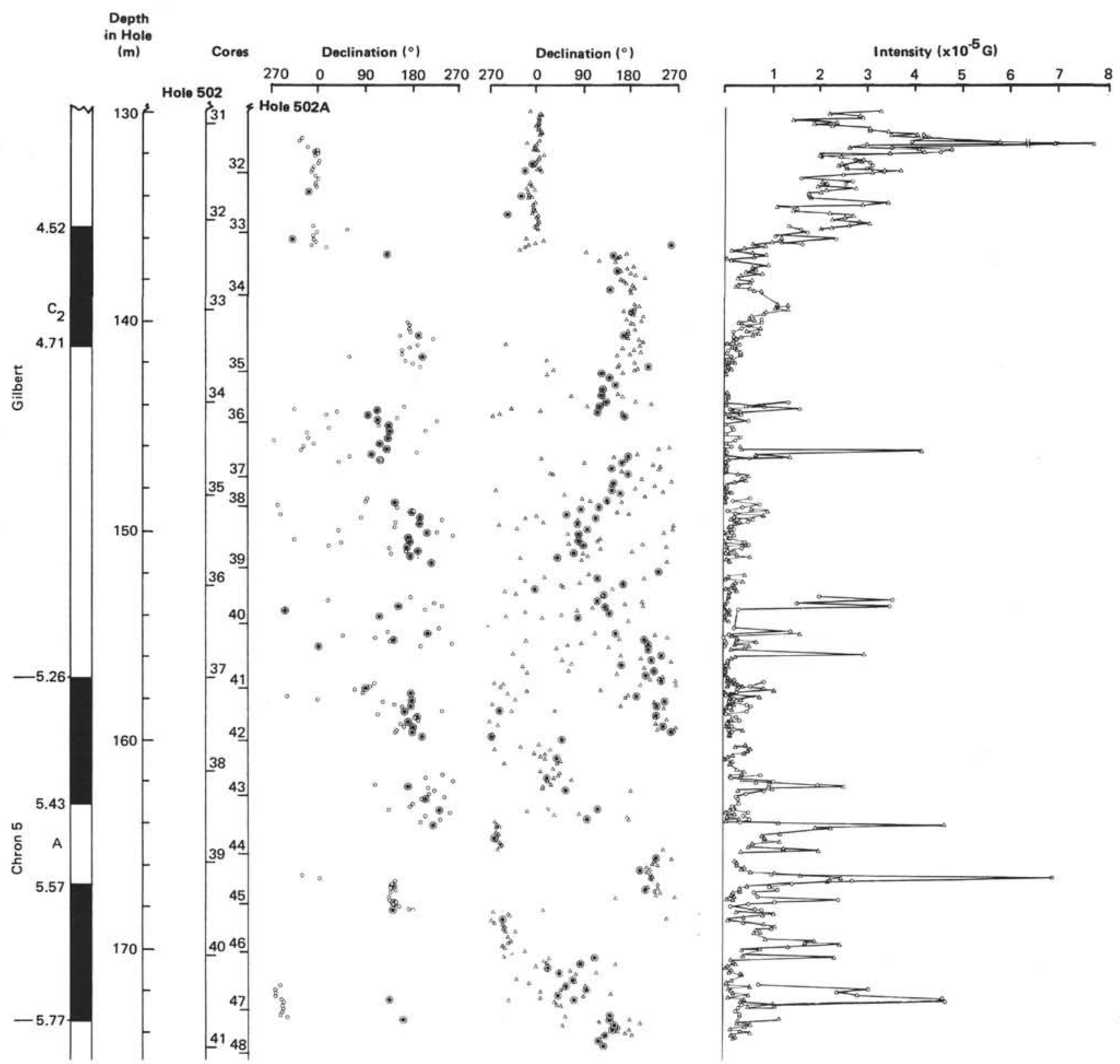

Figure 9. Paleomagnetic data from lower part of section at Site 502. See caption for Figure 8 for explanation of columns and symbols, except note that no adjustments to declinations and no magnetization polarity interpretations have been made except for Cores 502-32 to 502-34 and 502A-32 to 502A-35, which overlap with bottom of Figure 8. Geomagnetic polarity time scale at left shown only for reference.

fruitfully analyzed without azimuthal orientation of the cores.

\section{ACKNOWLEDGMENT}

We thank Barbara Keating for reviewing the manuscript.

\section{REFERENCES}

Haq, B. U., Worsley, T. R., Burckle, L. H., Douglas, R. G., Keigwin, L. D., Jr., Opdyke, N. D., Savin, S. M., Sommer, M. A., II, Vincent, E., and Woodruff, F., 1980. Late Miocene marine carbon- isotopic shift and synchroneity of some phytoplanktonic biostratigraphic events. Geology, 8:427-431.

LaBrecque, J. L., Kent, D. V., and Cande, S. C., 1977. Revised magnetic polarity time scale for Late Cretaceous and Cenozoic time. Geology, 5:330-335.

Mankinen, E. A., and Dalrymple, G. B., 1979. Revised geomagnetic time scale for interval 0-5 m.y. B.P. J. Geophys. Res., 84: 615-626.

Mankinen, E. A., Donnely, J. M., and Gromme, C. S., 1978. Geomagnetic polarity event recorded at $1.1 \mathrm{~m} . \mathrm{y}$. B.P. on Cobb Mountain, Clear Lake volcanic field, California. Geology, 6:653-656.

Watkins, N. D., 1968. Short period geomagnetic polarity events in deep-sea sedimentary cores. Earth Planet. Sci. Lett., 4:341-349. 


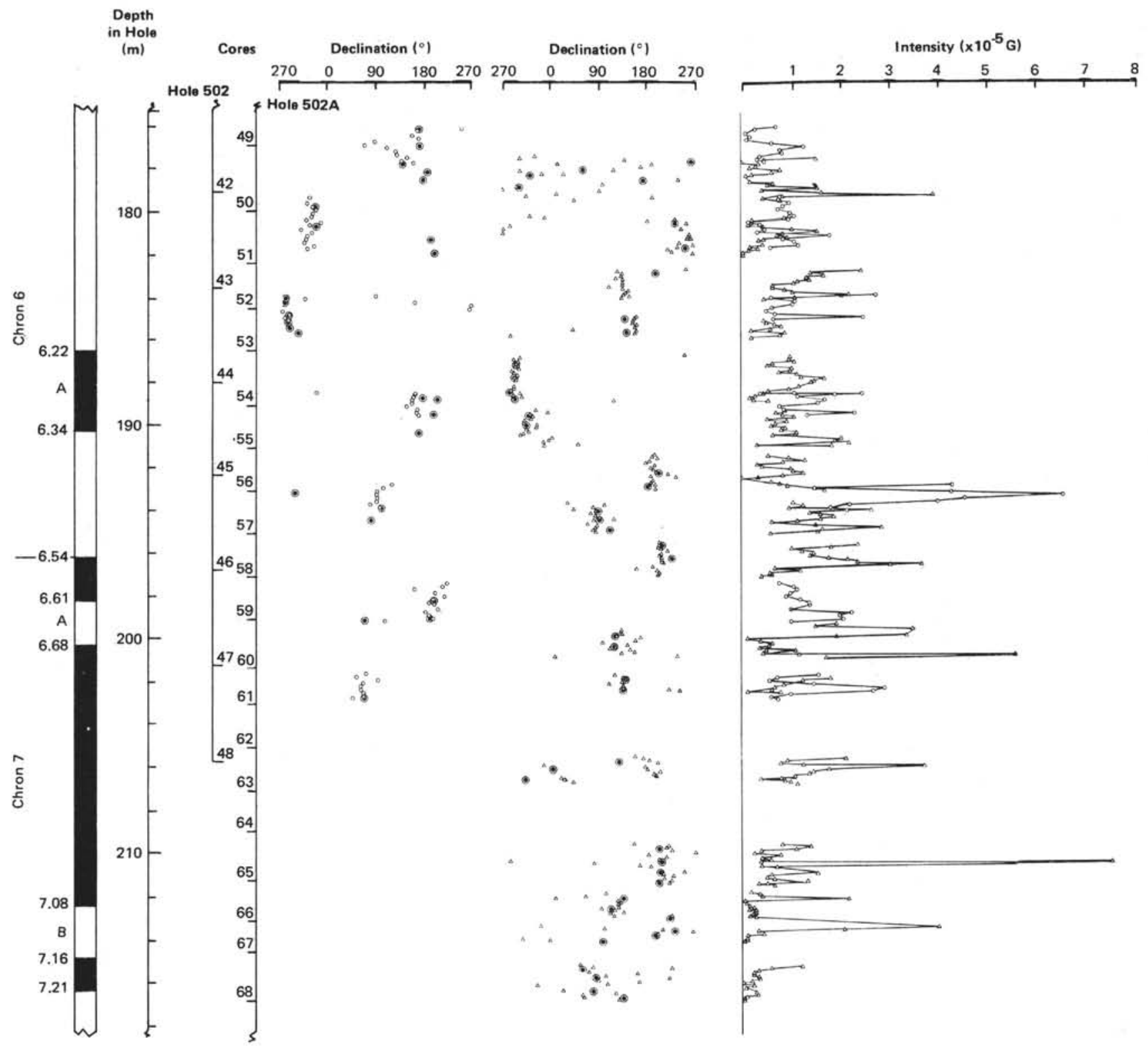

Figure 9. (Continued). 


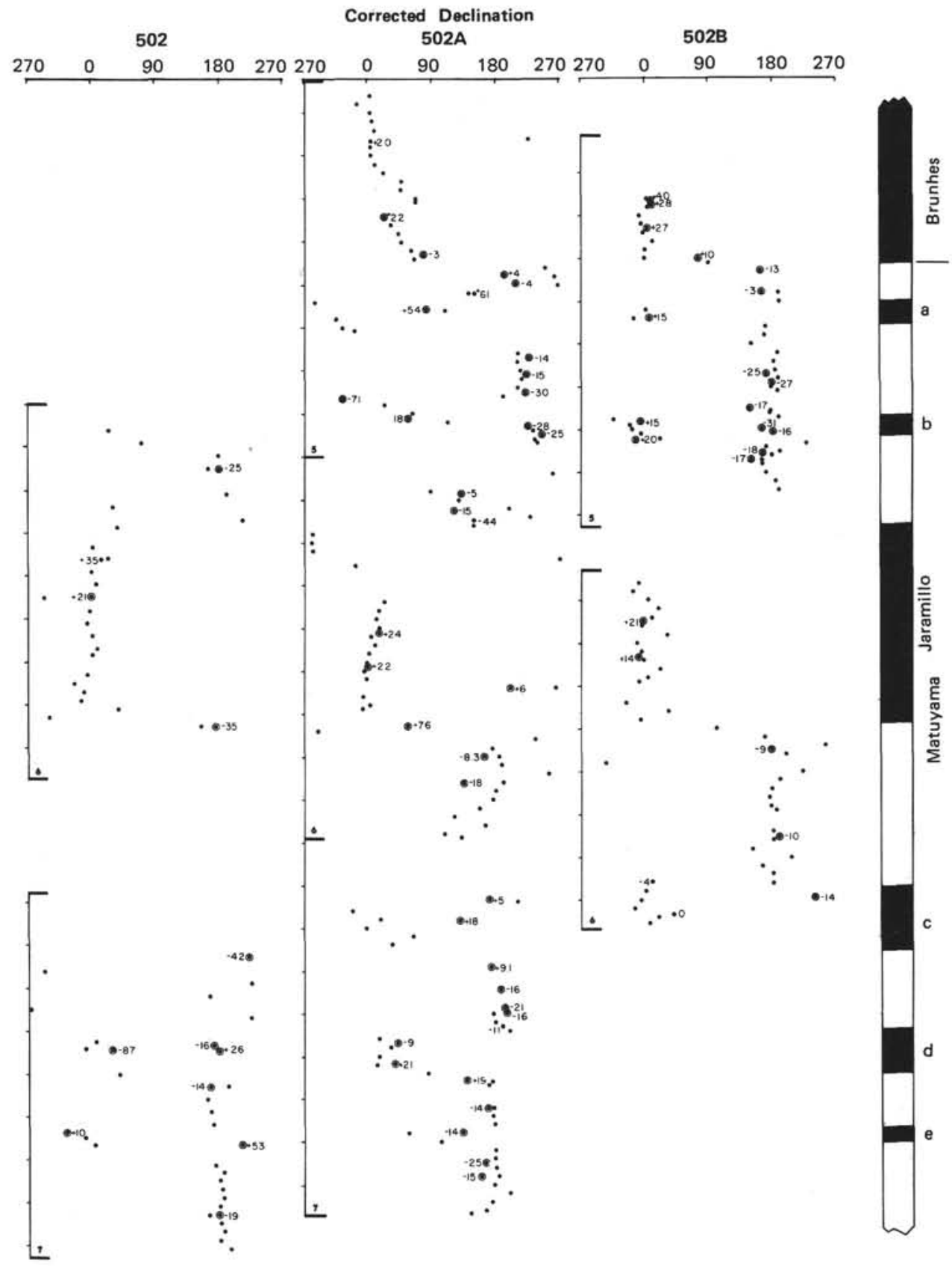

Figure 10. Long-core spinner magnetometer generated paleomagnetic directions from Holes 502, 502A, and 502B in the vicinity of the magnetozone correlated to the Jaramillo. Cores from different holes are correlated on the basis of magnetic data. See Site 502 Chapter for cored depth intervals; tick marks for each core are in units of 0.5 meter. Magnetosubzones of normal magnetization polarity, which may represent geomagnetic features not universally recognized, are informally labeled in polarity log as a, b, c, d, and e. Solid circles are sample magnetization directions. Declination directions within each core adjusted to average $0^{\circ}$ for normal polarity, $180^{\circ}$ for reversed polarity interpretation. Rotation of declination within several of the cores reflects twisting of the sediment during handling. 


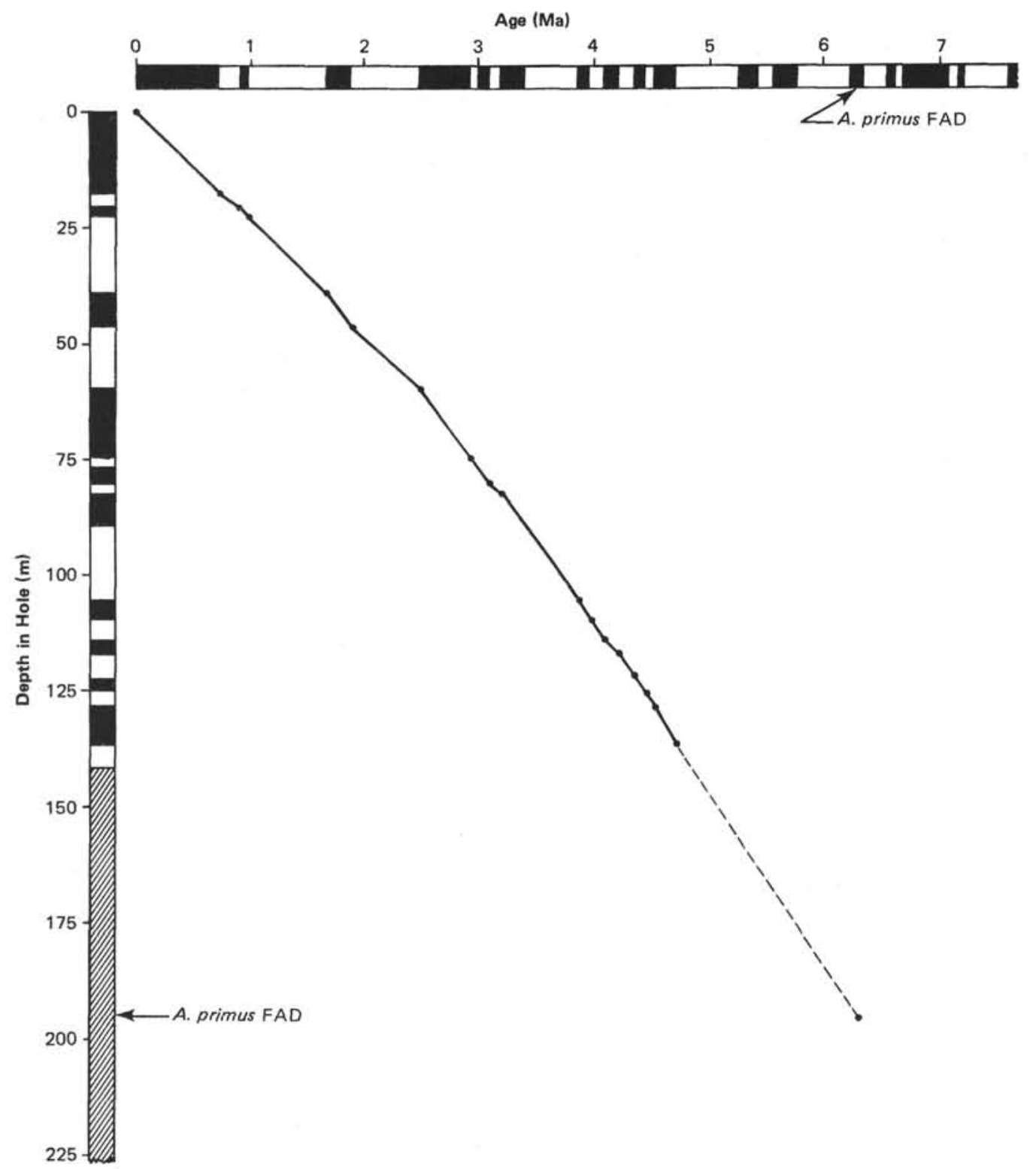

Figure 11. Sub-bottom depth to magnetozones at Site 502 plotted with respect to ages of their correlative chrons, according to the geomagnetic reversal time scale of LaBrecque et al., (1977) modified after Mankinen and Dalrymple (1979) for newly adopted decay constants. Tie points near base of the section are based on correlation of biostratigraphic datums to reversal scale described elsewhere (Haq et al., 1980, for A. primus). 